УДК $294.3(510)$

DOI: 10.18101/1994-0866-2019-2-20-30

\title{
НАЧАЛЬНЫЙ ПЕРИОД ПРОНИКНОВЕНИЯ, РАСПРОСТРАНЕНИЯ И КИТАИЗАЦИИ БУДДИЗМА В КИТАЕ*
}

\author{
(c) Чебунин Александр Васильевич \\ доктор философских наук, доцент, \\ Восточно-Сибирский государственный институт культуры \\ Россия, 670031, г. Улан-Удэ, ул. Терешковой, 1 \\ E-mail: chebunin1@mail.ru
}

Буддизм начинает проникать в Китай на рубеже I тысячелетия н. э. Данный процесс характеризовался сложным взаимодействием буддийского учения с высокоразвитой китайской культурой, где уже сложились устойчивые формы конфуцианской и даосской идеологии. Выделение базовых точек отсчета этого взаимодействия позволяет дифференцировать начальный процесс проникновения на несколько основных периодов: знакомство с буддизмом; проникновение буддизма в Китай, начавшееся с призванием буддистов императором Мин-ди; распространение буддизма в Китае, начавшееся с процессом воспроизводства буддийской модели личности среди китайцев и дать им историко-культурную характеристику. Соответственно, проблематика проникновения буддизма в Китай конкретизируется в этих трех аспектах и более полно характеризует процесс освоения буддийского учения китайским обществом. Одновременно все эти периоды пронизывает процесс китаизации буддизма, обусловливая адаптацию буддийского учения к китайскому менталитету и социально-культурной среде, результатом чего стало превращение буддизма в неотъемлемую часть традиционной китайской культуры.

Ключевые слова: буддизм; Китай; китаизация буддизма; китайский буддизм; распространение буддизма; китайская культура; конфуцианство; даосизм; переводческая деятельность.

Для цитирования:

Чебунин А. В. Начальный период проникновения, распространения и китаизации буддизма в Китае // Вестник Бурятского государственного университета. Философия. 2019. Вып. 2. С. 21-30.

Буддизм представляет собой одну из крупнейших идеологических систем в истории и современном мире, охватывая совокупность этических, религиозных и философских идей в вертикальном срезе, а также онтологических, антропологических и аксиологических идей в горизонтальном срезе. Его влияние на развитие человеческой цивилизации огромное, а ареал распространения обширный.

В этот ареал входит и Китай, одно из древнейших государств мира, демонстрирующий в настоящее время выдающиеся достижения в области экономики и культуры. Во многом эти достижения обусловливаются традиционной духовной культурой, которая позволяет принимать новые формы развития, приспосабливая общество к изменяющимся геополитическим условиям. В этом контексте процесс проникновения и китаизации буддизма в Китае, трансформации его в

* Исследование выполнено при финансовой поддержке РФФИ в рамках научноисследовательского проекта «Философская интерпретация и трансляция буддизма (на материале тибетской и китайской махаяны)», № 17-03-00250. 
традиционный элемент собственной культуры, с одной стороны, расширил и углубил содержание традиционной духовной культуры, с другой - дал китайскому обществу богатый опыт взаимодействия с инородной культурой в плане ее адаптации в интересах своего развития.

Дата начала проникновения буддизма в Китае представляет собой сложный вопрос в историко-методологическом плане. Проблема заключается в том, что считать за отправную точку начала проникновения, а также каким образом это проникновение соотносится с распространением буддизма в Китае. Это может быть, во-первых, первый контакт китайцев с буддистами; во-вторых, знакомство китайцев с буддийским учением; в-третьих, проникновение буддистов в Китай; в-четвертых, принятие китайцами буддизма в качестве религии или идеологии и, в-пятых, начало воспроизводства буддийской модели личности в Китае. Вместе с тем в зависимости от методологической позиции данная проблема может решаться по-разному.

Первый контакт китайцев с буддистами согласно записям «Сведений о трех сокровищах и исторических эпохах» (597 г.) носил легендарный характер. Во времена правления Цинь Шихуан-ди (秦始皇, 246-210 гг. до н. э.), основателя первой китайской империи, в Китай прибыли 18 монахов во главе с Ши Лифаном (释利防). Они привезли с собой сутры для проповедческой деятельности, однако Цинь Шихуан-ди приказал взять их под стражу, что вполне согласуется с той политикой идеологической централизации, которую он проводил. Ночью великан высотой в 6 чжанов (около 20 метров) разрушил тюрьму и выпустил монахов, после чего удивленный и напуганный император отпустил их с миром ${ }^{1}$.

Данный текст характеризуется краткостью и отсутствием важных деталей. Неизвестно, каким путем прибыли эти монахи, северным, из Центральной Азии, или морским, из Юго-Восточной Азии. Также не конкретизируется год их прибытия, хотя авторы четырехтомного труда «Китайский буддизм» указывают 218 г. до н. э. ${ }^{2}$ Несмотря на это, а также определенный мистицизм, вероятность данного события достаточно высока, поскольку как раз к этому времени относятся буддийские посольства индийского царя Ашоки. Тем не менее последствий от данного контакта для китайской культуры не было, буддизм не закрепился в китайской среде, поэтому считать это событие началом проникновения буддизма в Китай не приходится.

Факт первого знакомства китайцев с буддийским учением имеет уже более достоверный исторический характер. В «Записях о троецарствии» раздел «История Вэй» ссылается на «Историю Вэй» (魏略) Юй Хуаня (鱼䅈), где упоминается событие 2 г. до н. э., когда бошидицзы (博士弟子— чиновничье звание) Цзин Лу (景卢) от посланника Великих Юэчжи (Кушанское царство) И Цуня (伊存) получил устные наставления о буддийской сутре или о сутре Будды (浮屠经).

Данное событие также описывается весьма кратко, тем не менее авторитет источника не позволяет усомниться в достоверности описываемых фактов, поэтому в научной китайской среде считается вполне реальным и большинством

\footnotetext{
1 历代三宝纪 // 大正新修大藏经, № 2034, 15 цз. (Фэй Чанфан. Сведения о трех сокровищах и исторических эпохах).

2 中国佛教. 四辑, 上海: 东方出版中心, 1996. (Китайский буддизм: в 4 т.). Т. 1. С. 4.
} 
исследователей признается за начало проникновения буддизма в Китай. Источник не уточняет, где произошло это событие, то ли Цзин Лу был в Кушанском царстве, то ли И Цунь в самом Китае наставлял его, хотя большинство китайских исследователей склоняется ко второму варианту. Наибольшее же значение для них имеет упоминание «сутры Будды» в качестве первого письменного буддийского источника, представленного китайцу. В этом плане Фан Гуанчан считает «сутру Будды» первым буддийским текстом, переведенным на китайский язык, хотя в источнике не говорится конкретно о его переводе. Вполне возможно, что речь идет о компиляции буддийских сутр. Тан Юнтун более осторожно высказывается о наличие буддийских текстов на китайском языке в конце династии Западной Хань [5, с. 85-86].

Впрочем, данный зафиксированный факт знакомства китайцев с буддийским учением, несмотря на то, что имеет вполне достоверный исторический характер, еще не является доказательством первого знакомства китайцев с буддизмом. Прошло более века с тех пор, как император Хань У-ди открыл «Шелковый путь», по которому в Китай проникали не только западные товары, но и люди, среди которых обязательно должны были быть и буддисты, учитывая территорию распространения буддизма в то время. В самом начале правления У-ди в походе на сюнну была добыта статуя Будды, которую поместили во дворце и перед которой возжигали благовония ${ }^{1}$. Даже разведывательное путешествие Чжан Цяня (张骞) в 138-126 гг. до н. э. в западные страны должно было принести определенные сведения о буддизме. Поэтому вполне возможно, что наставления И Цуня лишь теоретически фиксировали ту информацию, с которой китайцам приходилось сталкиваться и до этого. Более того, факт знакомства с информацией еще не подразумевал восприятие ее в качестве элемента китайской культуры, поэтому признание факта знакомства китайцев с буддизмом, даже документально подтвержденного, в качестве начала проникновения и распространения буддизма в Китае можно считать с большими оговорками.

Проникновение буддистов в Китай в качестве отправной точки начала распространения буддийского учения в Китае также затруднительно, поскольку невозможно точно установить, когда первые буддисты прибыли в Китай, а также их дальнейший статус. Однако если это прибытие было официально легализировано и зафиксировано, тогда снимаются многие вопросы. Это понимали и китайские буддисты, выбрав за отправную точку проникновения буддизма в Китай легендарное приглашение буддистов императором Мин-ди (58-76 гг. н. э.). Согласно «Сведениям о трех сокровищах и исторических эпохах», в 64 г. императору приснился золотой человек в 6 чжанов (около 20 метров), который летал во дворце и испускал яркий свет. Утром император попросил чиновников растолковать свой сон, и один из них по имени Фу И (傅毅) сказал, что на Западе имеется божество по имени Будда и это должно быть оно. Император посчитал это правдой и отправил посольство, во главе которого были Цинь Цзин (秦景) и Ван Цзунь (王遵), в Индию за буддийской Дхармой. В Кушанском царстве посольство встретило буддийского монаха Кашьяпу Матангу (迦叶摩腾), который то ли перевел, то ли записал «Сутру в 42 чжана» (四十二章经). В 67 г. посольство вме-

1 历代三宝纪 // 大正新修大藏经, № 2034, 15 ц3. (Фэй Чанфан. Сведения о трех сокровищах и исторических эпохах). 
сте с Кашьяпой Матангой, сутрами и изображениями Будды вернулось в Китай в столицу Лоян, где был основан первый буддийский монастырь Белой лошади [2, ц3. 2]. Еще по одной версии вместе с Кашьяпой Матангой в Китай также прибыл буддийский монах Дхармаратна (Чжуфалань, 竺法兰) ${ }^{1}$. Таким образом, официально это были первые буддийские монахи, прибывшие в Китай.

Данное событие описано во многих источниках с небольшими расхождениями. Так, по годам сон Мин-ди датируется от 60 г., а возвращение посольства до 75 г. $^{2}$ Среди послов в «Сутре в 42 чжана»еще указан Чжан Цянь, живший за 2 века до описанных событий, а Моу-цзы в «Трактате о разрешении сомнений» упоминает Цай Иня (蔡愔). Подобные расхождения, а также преобладание буддийских источников, где описывается данное событие, вызывали и вызывают определенный скепсис в его отношении.

Японский исследователь Камато Сигэо указывает пять сомнительных моментов, которые, по его мнению, опровергают достоверность этого события [6, c. $12-13]$ :

Во-первых, по его версии, Мин-ди только из своего сна узнал о существовании Будды, хотя до этого тесно общался со своим братом Чуйским ван Лю Ином (楚王英), который поклонялся Будде, поэтому это событие само по себе противоречивое. Однако ни в одном источнике не указывается, что Мин-ди первый раз узнал о Будде из сна, там говорится, что император только попросил растолковать сон и согласился с версией Фу И, что может как раз наоборот доказывать о его знакомстве с буддизмом еще до сна.

Во-вторых, Камато Сигэо указывает на упоминание Чжан Цяня, якобы участвовавшего в посольстве, что также доказывает неправдоподобность данного события. Впрочем, это имя упоминается не во всех источниках, а наличие множества версий не исключает позднейших вставок для придания авторитетности. Сейчас трудно определить, кто действительно был в посольстве.

В-третьих, Камато Сигэо утверждает, что упомянутые Цинь Цзин и Ван Цзунь больше не встречаются в других источниках, что вызывает сомнение в их реальном существовании. Но если эти люди больше не сделали ничего выдающегося, кроме как участия в посольстве, отсутствие их упоминания в исторических документах вполне обосновано. Также нужно учитывать, что не все исторические документы дошли до нашего времени.

В-четвертых, Камато Сигэо утверждает, что Фу И, растолковавший сон императора Мин-ди, в то время был слишком молодым, чтобы служить во дворце. Однако в «Истории Поздней Хань», на которую он ссылается, нет указания на дату рождения Фу И. Впрочем там отмечается, что известный историк Бань Гу (班固), годы жизни которого известны точно (32-92 гг.), был учеником Фу ${ }^{3}$. Даже если признать, что Фу И был младше Бань Гу, что уже весьма сомнительно, то есть вероятность того, что в 60-х гг. Фу И вполне мог служить во дворце.

В-пятых, Камато Сигэо указывает, что во времена Мин-ди не было практики официальных посольств в западные страны. Этот довод тоже не выдерживает

\footnotetext{
1 历代三宝纪 // 大正新修大藏经, № 2034, 15 ц3. (Фэй Чанфан. Сведения о трех сокровищах и исторических эпохах).

2 中国佛教.四辑, 上海: 东方出版中心, 1996. (Китайский буддизм: в 4 т.). Т. 1. С. 5.

3 后汉书 (История Поздней Хань). Цз. 80.
} 
критики, поскольку к тому времени торговые отношения с западными странами продолжались почти два века, стороны были достаточно знакомы друг с другом, и ничто не мешало отправлять спорадические посольства.

Таким образом, скепсис Камато Сигэо недостаточно обоснован фактологическим материалом и не может опровергнуть факт призвания буддизма в Китай императором Мин-ди. Более того, в методологическом плане буддисты, признающие это событие в качестве отправной точки начала проникновения буддизма в Китай, занимают более обоснованные позиции. Поэтому призвание буддизма в Китай императором Мин-ди, вследствие чего в Китай прибыли буддийские монахи, вполне может быть признано за начало проникновения и распространения буддизма в Китае.

Факт принятия китайцами буддизма в качестве идеологии или религии также трудно установить, поскольку он упирается в формальные признаки. Поклонение императора У-ди статуе Будды, захваченной у сюнну, вполне могло быть формальным ритуалом «на всякий случай». Ни о каком принятии буддийского учения в данном случае нельзя говорить. Равным образом трудно установить, сколько китайцев могли заинтересоваться буддизмом в процессе торгово-культурного обмена с западными странами. В этом плане источники сохранили лишь упоминание о брате императора Мин-ди Чуйском ван Лю Ине (楚王英). В «Истории Поздней Хань» говорится, что Лю Ин в пожилые годы полюбил учение Хуан-ди и Лао-цзы, изучал учение Будды, придерживался постов и совершал жертвоприношения. Также упоминаются упасаки, мирские последователи, и шраманы, буддийские монахи, которые были в окружении Лю Ина ${ }^{1}$ [1, ц3. 42].

Сочетание буддизма с даосизмом в ранний период проникновения буддизма в Китай является наиболее характерной чертой этого периода. Поэтому неудивительно, что в источниках имя Будды сочетается с именами легендарного основателя даосского учения Хуан-ди, а также Лао-цзы и Чжуан-цзы. Однако весьма трудно судить, насколько элементы буддийского учения оказывали влияние на мировоззрение ранних адептов. Сам Лю Ин закончил жизнь самоубийством, что глубоко противоречит учению Будды и показывает поверхностное, формальное влияние буддизма на него. В этом аспекте совершение буддийских ритуалов было направлено на приобретение здоровья, счастья и благополучия, избегание несчастий, что как раз отражает обычное, мирское понимание религиозных культов.

Подобный утилитарно-формальный подход к буддизму в ранний период его проникновения и распространения позволяет выделить два аспекта его принятия. Во-первых, это принятие в качестве инструмента решения утилитарных вопросов, когда формальные ритуалы должны были помочь в жизни, и, во-вторых, принятие в качестве мировоззрения для самоизменения и формирования буддийской личности. В этом плане власть ханьского Китая явно поддерживала первый аспект, не только не ограничивая распространение буддизма, но и определенным образом поощряя его. Так, согласно «Истории Поздней Хань» император Мин-ди вернул шелк Лю Ину для помощи упасакам и шраманам ${ }^{2}$. С другой стороны, согласно «Жизнеописаниям достойных монахов» власть запрещала китайцам уходить в монастыри и становиться монахами [1, ц3. 9]. И хотя в этом вопросе нема-

\footnotetext{
1 后汉书 (История Поздней Хань). Цз. 42.

2 Там же.
} 
лую роль играли социально-экономические соображения, данный запрет ограничивал процесс содержательного восприятия буддизма в контексте формирования буддийской личности. Сангха наряду с Буддой и Дхармой являлась основой существования буддизма, сферой реализации духовной практики, поэтому отсутствие собственно китайской сангхи означало одностороннее, ограниченное восприятие, принятие и распространение буддизма в Китае.

Соответственно, даже приверженность буддизму императора Хуань-ди (桓帝, 147-167 гг.) лишь показывает окончательное формальное признание буддизма на территории Китая, принятия его в качестве религии для решения утилитарных вопросов, но не в качестве идеологии для формирования буддийской личности. Таким образом, принятие буддизма высшей властью отражает лишь конец проникновения буддизма в Китай и активизацию его распространения среди китайцев, в котором можно выделить два уровня: формально-культовое и содержательно-мировоззренческое распространение. Именно переход первого уровня во второй, формально-культового принятия буддизма в содержательномировоззренческое, характеризует окончание проникновения буддизма в Китай и начало его активного распространения и закрепления в китайской культуре.

Начало воспроизводства буддийской модели личности в Китае в качестве отправной точки распространения буддизма имеет более весомые методологические основания, поскольку любая религия и идеология обретают жизнь только через своих носителей. Формальное использование буддийских ритуалов для утилитарных целей показывает поверхностное восприятие буддийского учения, которое может легко быть отброшено в случае неэффективности. Однако принятие буддийского мировоззрения в качестве жизненных ориентиров уже является фактом закрепления буддизма в китайской культуре. Превращение буддизма в органический элемент китайской культуры заняло достаточно длительный период времени, и этот процесс определялся как качественными показателями, то есть степенью ориентации личности на буддийскую модель, так и количественными показателями, то есть количеством адептов с такой ориентацией.

Поскольку к моменту проникновения буддизма в Китай последний представлял собой уже достаточно развитую цивилизацию, в которой сложились две базовые традиционные модели личности - конфуцианская и даосская, выбор буддийской модели обусловливался неудовлетворенностью ими. Буддизм смог предложить китайцам то, чего не хватало в традиционных моделях, в результате буддизм был вынужден не противопоставлять себя традиционным учениям, а показывать свое преимущество в сочетании с ними. В этом контексте направленность на трансцендентное сблизила буддизм и даосизм настолько, что первый зачастую воспринимался как одно из направлений последнего. Благодаря этому буддизм смог адаптироваться в китайской культурной среде и продвигать собственные ценности, ориентация на которые и определяла буддийскую модель личности. Соответственно, степень доминирования буддийских ценностей в сравнении с традиционными ценностями весьма сложно установить, особенно на первых этапах распространения буддийского учения в Китае. Тем не менее статус монаха, послушника или мирского последователя буддизма уже может являться определенным маркером для такого установления.

Первым китайцем, получившим буддийский статус, считается Янь Фодяо (严 佛调). Точные годы его жизни не известны, а его деятельность приходилась на 
вторую половину II в. В 181 г. он записал перевод Ань Сюаня (安玄) «Сутры зеркала Дхармы» (法镜经), впоследствии сам перевел «Вималакирти-нирдеша сутру» (古维摩经), а также написал «Разделы о десяти мудростях шраманера» (沙弥 十慧章句). Поскольку в то время еще не сложился китайский ритуал принятия пострига в монахи, в точности неизвестно, какие обеты он принял, и неясен его официальный статус. В «Жизнеописаниях достойных монахов» он указан как монах (沙门), а в «Записках о трех сокровищах и исторических эпохах» - как упасака (清信士).

Подобная неопределенность сохранялась вплоть до 249 г., когда из центральной Индии в Китай прибыл буддийский монах Дхармакала (Танькэцзяло, 县柯迦 罗). Он считается первым патриархом китайской буддийской школы уставов (люйцзун, 律宗), а с его именем связано оформление китайского ритуала посвящения в монахи согласно традиционному буддийскому уставу. И первым китайцем, принявшим постриг в соответствии с традиционным буддийским уставом, стал Чжу Шисин (朱士行). В 260 г. Чжу Шисин отправился в западный край в поисках оригинальных буддийских текстов, заложив тем самым многовековую традицию путешествий китайских буддистов в поисках «истинного буддизма». Переправив найденную «Сутру сияющей праджняпарамиты» (放光般若经) в Китай, сам Чжу Шисин остался на западе до своей смерти.

Окончательное формирование китайской буддийской сангхи, ставшей институтом воспроизводства буддийской модели личности, произошло с закреплением в сангхе статуса послушницы и монахини. Первой китаянкой, получившей буддийский статус, стала Цзинцзянь (净检). После сорока лет статуса послушницы в 357 г. она и еще четыре женщины приняли полные обеты монахинь, завершив тем самым долгий процесс институционализации китайской буддийской сангхи, которая с тех пор стала неотъемлемой частью социальной структуры китайского общества.

Таким образом, к началу IV в. буддизм в Китае окончательно вошел в культурную жизнь в качестве целостной социальной системы. Этот процесс вхождения буддизма в Китай занял длительное время и прошел через несколько этапов. Выделение этих этапов позволяет конкретизировать проблему проникновения и распространения буддизма в Китае, характеризуя ключевые моменты взаимодействия китайской культуры с буддизмом. Во-первых, это первое официальное знакомство с буддийским учением во 2 г. до н. э. бошидицзы Цзин Лу от посланника Великих Юэчжи (Кушанское царство) И Цуня. Во-вторых, это начало официального проникновения буддизма в Китай по приглашению императора Минди в 67 г. В-третьих, это начало распространения буддизма в Китае, соотносящееся с получением Янь Фодяо буддийского статуса. Данные начальные точки отчета знакомства, проникновения и распространения обусловливают сложный процесс адаптации буддийского учения к китайским культурным реалиям, его трансформации и китаизации, превращения в органическую часть китайской культуры.

Соответственно, процесс китаизации буддизма начинается с момента его восприятия китайским менталитетом, где определяющим является языковая адаптация буддийских понятий на китайский язык. В результате этого именно переводческая деятельность стала ведущим фактором китаизации и адаптации 
буддийского учения в Китае. Л. Е. Янгутов отмечает: «История переводов буддийских сутр неотделима от истории распространения буддизма в Китае» [3, c. 21]. Подобная связь переводческой деятельности и китаизации буддизма проходит красной нитью через всю историю буддийского учения в Китае, определяя основные вехи этой самой истории, где ведущее значение имели переводчики и их деятельность.

Первыми буддийскими переводчиками в Китае были иностранные буддисты, начавшие проникать в Китай после призвания императора Мин-ди. Традиционно выделяют два пути, по которым буддисты проникали в Китай: 1) северный сухопутный, широко известный «Шелковый» путь, связывающий Китай с Центральной и Средней Азией, а через них с Индией; 2) южный морской путь, связывающий Китай с Южно-Восточной Азией и Индией. На первом этапе проникновения буддизма в Китай значение северного пути было преобладающим. Согласно историческим записям большинство известных буддистов-переводчиков прибыли в Китай именно по этому пути, проходящим по многочисленным центральноазиатским княжествам, среди которых выделяются Парфия и Кушанское царство, сыгравшие важную роль в передаче буддийского учения китайцам.

Южный морской путь также играл важную роль в деле проникновения буддизма в Китай. Некоторые исследователи считают, что именно по южному пути прибыли буддисты, которые были при Чуйском ван Лю Ине. Многочисленные археологические находки также доказывают наличие культурных связей между Индией и Китаем в I-III вв., проходящих по южному морскому пути [5, с. 92-99]. Однако этот маршрут проникновения буддизма в Китай вероятнее всего был характерен для народного уровня, поэтому не нашел серьезного отражения в исторических документах. В то же время культурные и политические связи с центрально-азиатскими княжествами играли важную роль во внешней политике Китая, ведущего постоянные войны с северными кочевниками. Поэтому политика центральной власти, в том числе и касающаяся культурных связей с потенциальными союзниками, строго фиксировалась в исторических документах. Вполне возможно, что и та поддержка буддизму, которую оказывала императорская власть, была во многом обусловлена прагматическими политическими интересами.

В последнее время еще выделяют и южный сухопутный путь проникновения буддизма в Китай, соединяющий центрально-азиатские княжества и ЮгоВосточную Азию через Сычуань, Юньнань и Мьянму. Но как и южный морской путь, он в основном служил торговым интересам [5, с. 100-101].

Все эти торговые пути и обеспечили Китай как буддистами, так и переводчиками буддийской литературы, поскольку проповедческая деятельность была важной частью религиозной деятельности буддийской сангхи. Начиная с I в. многочисленные буддийские тексты постепенно переводят на китайский язык. Первой буддийской сутрой, переведенной на китайский язык, считается «Сутра в 42 чжана», которую перевели первые официально призванные буддисты Кашьяпа Матанга и Дхармаратна. В настоящее время известно пять списков этой сутры, имеющие определенные отличия. Тем не менее эта сутра уже позволяет судить о начале процесса китаизации буддийского учения и его основных трудностях [2, с. 100-101].

Самой главной трудностью, с которой столкнулись первые переводчики, являлось коренное отличие китайского языка от санскрита, что затрудняло фонетическую передачу как имен, так и базовых понятий, отсутствующих в китайской духов- 
ной культуре. В итоге одна часть понятий начинает транскрибироваться, а другая заменяться китайскими понятиями, передающими основной смысл.

В первом случае это были незаменимые имена или термины, наподобие Будда (фото, 佛陀), шрамана (шамэнь, 沙门), архат (алохань, 阿罗汉), анагамин (анахань, 阿那含), сакритагамин (сытохань, 斯陀含), сротопанна (сюйтохуань, 须陀洹) и т. д. ${ }^{1}$ Причем специфика иероглифической письменности позволяла записывать похожие и одни и те же звуки через разные иероглифы, в результате одно слово могло быть записано различным способом. Например, имя Будда записывалось как сюту (休屠), футо (浮陀), футу (浮图), футоу (浮头), бото (勃陀), бодо (勃㭈), буто (部 陀), муто (母陀), модо (没驮) и т. д. ${ }^{2}$ Наряду с этим использовались и переводы имени Будды, такие как Пробужденный (цзюечжэ, 觉者) и Мудрец (чжичжэ, 智者). Разные переводчики использовали различные варианты, особенно если не знали переводов предшественников. Подобные расхождения существовали длительный исторический период до определенной унификации, проведенной известными переводчиками. Однако на начальном этапе об унификации понятий говорить не приходилось.

Во втором случае отсутствие базовых буддийских понятий в китайской духовной культуре, приводившее к полному непониманию их смысла, обусловливало подбор китайских терминов, более или менее соответствующих по содержанию. Если различные индийские философские школы, даже с совершенно различными мировоззренческими позициями, прекрасно ориентировались в философских понятиях общей индийской духовной культуры, то передача этих понятий на китайский язык ничего не говорила китайцам, пока тот не познакомится с основами философских учений. Поэтому для решения этой проблемы на первых этапах приходилось подбирать близкие по содержанию китайские понятия, что в определенной степени искажало первоначальный смысл всего буддийского учения. Поскольку в китайской культуре близкие мировоззренческие концепции были выдвинуты даосизмом, то неудивительно, что именно даосские термины были востребованы в первую очередь. Так, понятие «нирвана» первоначально переводилось как недеяние (увэй, 无 为) - базовое даосское понятие, впоследствии использовались понятия «угасание» (меду, 灭度), «покой и угасание» (цзиме, 寂灭), «не-рождение» (бушэн, 不生), «спокойствие и радость» (аньлэ, 安乐) и т. д. ${ }^{3}$ Однако в конечном итоге в китайских буддийских текстах возобладал оригинальный термин «нирвана» (непань, 涅槃), также первоначально имевший различные варианты (нихуань, 泥洹; нипань, 泥畔; непаньна, 涅槃那 и др.). Подобный переводческий метод подбора подходящего по смыслу понятия получил название гэ-и (格义) и явился необходимым этапом адаптации буддийского учения к китайской духовной культуре.

В конечном итоге начальный период буддийской переводческой деятельности характеризовался отсутствием строгой унификации терминологии. Свободное использование понятий и их различных форм, с одной стороны, затрудняло восприятие буддийского учения, приводило к разночтению и разногласию, но, с другой -

1 佛学大词典. Большой буддийский словарь [Электронный pecypc]. URL: https://foxue.51240.com (дата обращения: 03.03.2019).

${ }^{2}$ Там же.

${ }^{3}$ Там же. 
позволяло отфильтровать наиболее удачные варианты, выбрать наиболее точные по содержанию термины. По мере углубления знакомства китайцев с буддизмом среди буддийских понятий все более преобладали оригинальные, транскрипционные варианты, воспринимаемые уже как знакомые элементы учения, что обусловливало становление собственной формы китайского буддизма.

Начиная со второй половины II в. поток буддийских миссионеров и переводчиков в Китай значительно усилился. Иностранные буддисты получали широкую поддержку императорской власти, им предоставлялись площадки и помощники для переводческой деятельности, что обусловило широкое привлечение к буддийскому учению грамотных китайцев. Вполне возможно, что многие из них проникались буддийскими идеями уже в процессе переводческой деятельности, становясь активными сподвижниками и проповедниками буддизма в Китае. Ярким примером этого служит Янь Фодяо.

Среди первых буддийских переводчиков в Китае абсолютно преобладали иностранцы. Из них наиболее известны Ань Шигао (安世高), Локакшема (支娄迦谶), Чжицянь (支谦), Чжу Фошо (笈佛朔), Ань Сюань (安玄), Чжи Яо (支曜), Кан Мэнсян (康孟详), Кан Сэнхуэй (康僧会). К тому времени буддийская литература уже поражала своим количеством, поэтому выбор текстов для перевода определялся личным пристрастием переводчика и его интересами. Среди переведенных на китайский язык буддийских сутр были как хинаянские, так и махаянские, принадлежавшие различным направлениям [1, с. 271]. Все это позволяло китайцам познакомиться с буддийским учением во всем его разнообразии и постепенно выбрать те концепции, которые наиболее соответствовали их духовным запросам. По мере распространения буддизма в Китае процесс его теоретической китаизации органически переходил в процесс социально-политической и экономической китаизации, отражавший уже более поздние этапы распространения буддизма в китайском обществе. Становление собственной китайской формы буддизма в виде устойчивых институтов китайских буддийских школ Чань (禅宗) и Чистой земли (Цзинту, 净土宗) можно считать окончанием периода проникновения, распространения и китаизации буддизма в Китае.

Таким образом, начальный период проникновения, распространения и китаизации буддизма в Китае представлял собой довольно сложный процесс культурного и религиозно-философского взаимодействия китайского общества с внешними культурными элементами. До этого китайская цивилизация сталкивалась с менее развитыми культурами, от которых могла перенимать лишь отдельные элементы материальной культуры, позиционируя себя в качестве духовного центра цивилизационного влияния. Однако в отношении буддизма китайская культура встретила высокодуховное содержание, которое было способно восполнить определенные пробелы собственных традиционных учений, удовлетворяя духовные запросы сотериологического плана. Данный процесс распространения и адаптации буддийского учения к китайским культурным реалиям проходил достаточно длительное время, где можно выделить несколько культурно-исторических периодов и точек отчета. Во-первых, это период знакомства с буддизмом, официально начавшийся с получения Цзин Лу от посланника И Цуня устных наставлений о буддийской сутре и продолжавшийся до конца периода распространения буддизма в Китае. Во-вторых, это период проникновения буддизма в Китай, официально начавшийся с призванием буддистов императором Мин-ди. В-третьих, это период распространения буддизма в Китае, 
начавшийся с процессом воспроизводства буддийской модели личности среди китайцев, первым среди которых официально считается Янь Фодяо. Китаизация же буддизма пронизывает все эти периоды, обусловливая адаптацию буддийского учения к китайскому менталитету и социально-культурной среде, результатом чего стало превращение буддизма в неотъемлемую часть традиционной китайской культуры.

Литература

1. Введение в буддизм / ред.-сост. В. И. Рудой. СПб.: Лань, 1999. 384 с.

2. Чебунин А. В. История проникновения и становления буддизма в Китае. Улан-Удэ: ИПК ВСГАКИ, 2009. $278 \mathrm{c}$.

3. Янгутов Л. Е. Традиции Праджняпарамиты в Китае. Улан-Удэ: Изд-во Бурят. гос. ун-та, 2007. $272 \mathrm{c}$.

4. (日)鎌田茂雄. 简明中国佛教史. 郑彭年译, 上海: 上海译文出版社, 1986. (Камато Сигэо. Краткая история китайского буддизма).

5. 中国佛教通史. 赖永海主编. 第一卷, 南京: 江苏人民出版社, 2010. (Всеобщая история китайского буддизма: в 15 т. / под ред. Лай Юнхаят. Т. 1).

\title{
INITIAL PERIOD OF PENETRATION, DISTRIBUTION, AND SINICIZATION OF BUDDHISM IN CHINA
}

\author{
Aleksandr V. Chebunin \\ Dr. Sci. (Philos.), A/Prof., \\ East-Siberian State Institute of Culture \\ 1 Tereshkovoy St., Ulan-Ude 670031, Russia \\ E-mail: chebunin1@mail.ru
}

Buddhism begins to penetrate into China at the turn of the first millennium AD. This process was characterized by a complex interaction of Buddhist doctrine with the highly developed Chinese culture, where stable forms of Confucian and Taoist ideology the had already formed. The division of this interaction into base points allows us to specify the process of penetration into several main periods and give them historical and cultural description. The first period was an acquaintance with Buddhism. The second period was Buddhism penetration into China, which began with the invoking Buddhists by the emperor Mingdi. The third period was characterized by the spread of Buddhism in China and the processes of reproducing the Buddhist model of personality among the Chinese. These three periods more fully describes Buddhism penetration into China and acceptation of Buddhist doctrine by Chinese society. At the same time, all these periods permeated the process of Buddhism sinicization, and determined the adaptation of Buddhist doctrine to the Chinese mentality and socio-cultural environment. As a result Buddhism became an integral part of traditional Chinese culture.

Keywords: Buddhism; China; sinicization of Buddhism; Chinese Buddhism; spread of Buddhism; Chinese culture; Confucianism; Taoism; translation practice. 